\title{
Evaluation of Cytokines Levels and Lung Function in Patients Undergoing Coronary Artery Bypass
}

Dear Editor,

First, we congratulate the authors for the article entitled "Evaluation of cytokines levels and lung function in patients undergoing coronary artery bypass," recently published in the Revista Brasileira de Anestesiologia 1.

The importance of knowing the inflammatory status of patients undergoing cardiac surgery post-operatively is due to the fact that it can influence - besides the variables outlined in the study - the duration of mechanical ventilation and ICU stay, which was demonstrated by Kilger et al. ${ }^{2}$ The authors found that patients who received doses of hydrocortisone in postoperative period of cardiac surgery had low levels of IL-6 and shorter ICU stay compared to those who received no treatment.

However, the preoperative evaluation of brain natriuretic peptide (BNP) has been shown to be a better predictor of clinical outcomes in patients undergoing cardiac surgery, compared to inflammatory markers. This result is evident in the study by Ganem et al. ${ }^{3}$, which evaluated the levels of BNP, IL-6, IL-8, P-selectin, ICAM, and C-reactive protein and correlated them with immediate clinical outcomes in patients undergoing cardiac surgery. The study showed that elevated BNP levels correlate with longer ICU stay, duration of mechanical ventilation, and use of dobutamine. Plasma levels of BNP > $190 \mathrm{pg} \cdot \mathrm{mL}^{-1}$ are an independent predictor of ICU stay for longer than five days, which is not seen in this same period with the use of inflammatory factors. Therefore, the inclusion of BNP evaluation during the postoperative period in future studies is interesting to correlate it with ECC time.

Similarly to the finding of Machado et al. ${ }^{1}$ that the increase in the absolute values of IL- 6 are related to a longer ECC and varying levels of IL-8 are related to a longer duration of surgery, Liu et al. ${ }^{4}$ correlated such inflammatory markers with the duration of mechanical ventilation in children with renal failure undergoing cardiac surgery and found levels of IL-6 and IL-8 significantly higher in patients who required a longer time on mechanical ventilation.
Another important and influential factor regarding the inflammatory levels in these patients is the ventilation system used. Oliveira et al. ${ }^{5}$ compared cytokine levels in bronchoalveolar lavage in two groups of patients without lung disease who were mechanically ventilated at the ICU after surgery. One group used low tidal volume ventilation $\left(5-7 \mathrm{~mL} . \mathrm{kg}^{-1}\right)$ and the other high tidal volume (10-12 $\left.\mathrm{mL}^{\mathrm{kg}} \mathrm{k}^{-1}\right)$. The study showed that using a high tidal volume significantly increases the levels of IL-8 and TNF- $\alpha$.

Thus, we conclude that despite these elevated inflammatory markers present primarily regarding CEC, since the tidal volume ranged between 6 and $8 \mathrm{~mL}^{\mathrm{kg}}{ }^{-1}$ in patients undergoing cardiac surgery, other factors such as duration of mechanical ventilation during surgery and ventilation strategy adopted may also contribute to changes in absolute levels of these cytokines, as well as clinical outcomes in the immediate postoperative period.

Soraia Genebra Ibrahim

Physical Therapist at Intensive Care Unit, Specialist in Intensive Care Therapy, Hospital Moinhos de Vento.

Luiz Alberto Forgiarini Junior Professor of Physical Therapy, Centro Universitário Metodista (IPA); Student, PhD Program of Post-Graduation in Respiratory Sciences,

Universidade Federal do Rio Grande do Sul (UFRGS);

Researcher, Laboratory of Lung and Airway, Hospital de Clinicas de Porto Alegre (HCPA).

Elaine Aparecida Félix, PhD Associate Professor of Anesthesiology, Department of Anesthesia, Universidade Federal do Rio Grande do Sul (UFRGS); Head of Anesthesiology Service and Perioperative Medicine, Hospital das Clínicas de Porto Alegre (HCPA). 


\section{REFERÊNCIAS/REFERENCES}

01. Machado LB, Negri EM, Bonafé WW, Santos LM, Malbouisson LMS, Carmona MJC - Avaliação dos níveis de citocinas e da função pulmonar de pacientes submetidos à cirurgia cardíaca com circulação extracorpórea. Rev Bras Anestesiol, 2011;61(3):275-285. 
02. Kilger E, Heyn J, Beiras-Fernandez A, Luchting B, Weis F - Stress doses of hydrocortisone reduces systemic inflammatory responses in patients undergoing cardiac surgery without cardiopulmonary bypass. Minerva Anestesiol 2011;77(3):268-274.

03. Ganem F, Serrano CV, Fernandes JL et al. - Preoperative B-type natriuretic peptide, and not the inflamation status, predicts na andverse outcome for patients undergoing heart surgery. Interact Cardiovasc Thorac Surg, 2011;12(5):778-83.
04. Liu KD, Altmann C, Smits G, Krawczeski CD, Edelstein CL, Devarajan $P, S$ Faubel - Serum Interleukin-6 and interleukin-8 are early biomarkers of acute kidney injury and predict prolonged mechanical ventilation in children undergoing cardiac surgery: a case-control study. Crit Care, 2009;13(4):R104.

05. Oliveira RP, Hetzel MP, Silva MA, Dallegrave D, Friedman G - Mechanical ventilation with high tidal volume induces inflammation in patients without lung disease. Crit Care, 2010;14(2):R39. 